Journal of Jazz Studies vol. 7, no. 1, pp. 28-46 (Spring 2011)

\title{
"Harlem Air Shaft": A True Programmatic Composition?
}

\author{
Edward Green
}

In a 2007 article for Ongakugaku, the journal of the Musicological Society of Japan, I wrote at some length on the motivic structure of Duke Ellington's "Harlem Air Shaft." My purpose was to accent the "absolute" aspect of the music: to shed light on its bold compositional design. In this essay, I consider the question of the authenticity of "Harlem Air Shaft" as programmatic music. To resolve that question, it is important to have in mind the purely formal design of the composition, so I sketch it here.

As I suggested in my earlier essay, "Harlem Air Shaft" has an abstract design analogous to a concrete experience: namely, reading a book. First, we meet a "Table of Contents," a series of chapter titles. These are exceedingly short. Then, the chapters arrive, fleshing out and developing the hints provided in the titles.

Here is how these parallels work. First we hear a 12-bar Intro divided into three 4-bar segments-respectively in Ab, C, and E major. The sudden shifts of key place these short segments in sharp relief, highlighting how different they are in terms of timbre, rhythm, and melodic contour. Then, a series of 32-bar choruses follows. They are all in $\mathrm{A} b$, and take up-now without modulation- the musical ideas presented earlier. Chorus I develops the first segment of the Intro; Chorus II, the second; Chorus III, the third; and-to round it off-Chorus IV (the "shout chorus") develops the opening four measures of Chorus I. Thus, the opening 16 measures of the composition, considered as four separate 4-bar units, are the "titles," and foreshadow the main "chapters" of the work as a whole.

Nothing in all of previous jazz composition compares to this audacious structural plan. To go even further: among the European classics, perhaps only Beethoven's Op. 133, the Grosse Fuge, presages it. Yet unlike Beethoven's masterpiece for string quartet, for which no programmatic content has ever been suggested, "Harlem Air Shaft" is perhaps the Ellington piece most frequently thought of in programmatic terms. And for good reason-among all of Ellington's works for which we have a direct programmatic statement from the composer, this particular "story" has been reprinted more than any other.

\footnotetext{
${ }^{1}$ Edward Green, "Duke Ellington and the Oneness of Opposites: A Study in the Art of Motivic Composition,” Ongakugaku 52/2 (Fall 2007): 1-18.
} 
The detailed program for "Harlem Air Shaft" appeared originally in Richard O. Boyer's serialized portrait of Ellington ("The Hot Bach") in three consecutive issues of The New Yorker in the summer of 1944. Ellington's lengthy "storyline," Boyer says, was given on a train as the band was traveling between gigs. A group of passengers gathered around and asked question after question about their favorite pieces, including "In A Sentimental Mood," "Clarinet Lament," "Solitude," "Saturday Night Function," and "Awful Sad."

Duke did not provide narrative content for any of these works; his comments merely convey the circumstances under which they were composed. We learn, for example, that "Solitude" was written in Chicago while he was waiting for a recording session to begin, and that "Awful Sad" was composed late at night on the piano. But for "Harlem Air Shaft," he felt impelled to give a very detailed programmatic picture:

"Take 'Harlem Air Shaft," Duke said. "So much goes on in a Harlem air shaft. You get the full essence of Harlem in an air shaft. You hear fights, you smell dinner, you hear people making love. You hear intimate gossip floating down. You hear the radio. An air shaft is one great big loudspeaker. You see your neighbor's laundry. You hear the janitor's dogs. The man upstairs' aerial falls down and breaks your window. You smell coffee. A wonderful thing is that smell. An air shaft has got every contrast. One guy is cooking dried fish with rice and another guy's got a great big turkey. Guy-with-fish's wife is a terrific cooker but the guy's wife with the turkey is doing a sad job." Duke laughed. "You hear people praying, fighting, snoring. Jitterbugs are jumping up and down always over you, never below you. That's a funny thing about jitterbugs. They're always over you. I tried to put all that in 'Harlem Air Shaft."'

\section{THE CONTROVERSY}

For many years, it has been a scholarly commonplace to assert that Ellington made all this up after he composed the music. The implication is that this narrative, however charming and engaging on its own terms, bears little if any

\footnotetext{
${ }^{2}$ This quotation is found in the second New Yorker installment, published July 1, 1944. The entire set is reprinted in Mark Tucker, ed., The Duke Ellington Reader (New York: Oxford University Press, 1993), 214-245; the quote is on page 235.
} 
direct relevance to the work. ${ }^{3}$ From this perspective, Ellington's words reflect not what compelled him to compose the music, but how the piece, once composed, affected him years later. The story Boyer presents, on this account, would merely be Ellington's delayed verbal "signifying" on a previously self-sufficient instance of music.

On the surface, there is much to recommend this view. Obviously, there is a substantial time gap: the Boyer interview is from 1944, and "Harlem Air Shaft" was first recorded July 22, 1940, at the Victor studios in New York. (The record was released in late August as Victor 26731, with "Sepia Panorama” on the reverse side.) Moreover, the score - in light pencil in Ellington's own hand-reveals that "Once Over Lightly" was the original title (see Figure 1). "Harlem Air Shaft" was written in later by copyist Tom Whaley, who used a significantly darker, heavier pencil. ${ }^{4}$ This score, from which parts were derived for the recording session, is held in the Ellington Collection at the Smithsonian Institution. ${ }^{5}$ Whaley could not have amended the score before the recording session, since he did not join the Ellington organization until 1941.

A third point has been raised by revisionist critics: the Victor recording logs for this July 22nd session apparently give yet a third title for the work: "Rumpus in Richmond.” Eventually, another piece (recorded at the same session) would receive that designation, and what we now know as "Rumpus in Richmond" was put down in the session logs as "Brassiere."

Let us take a closer look at these matters. Firstly, "Rumpus in Richmond" clearly cannot hold up as an authentically earlier title for "Harlem Air Shaft." To begin with, no member of the band has ever been cited remembering "Harlem Air Shaft" as "Rumpus in Richmond." More saliently, the words "Rumpus in Richmond" cannot be found anywhere on the manuscript, or on any of the parts. By contrast, "Harlem Air Shaft" is written on both the score and all the parts.

\footnotetext{
${ }^{3}$ For example, in the liner notes to the RCA Bluebird 3-CD set The Blanton-Webster Band, Mark Tucker writes: "Ellington once gave a detailed sensory description of the place that supposedly inspired this piece, but there is little correspondence between his words and his music." Eddie Lambert has similar doubts. In his Duke Ellington: A Listener's Guide (Lanham, MD: Scarecrow Press, 1999), page 90, he writes of Ellington's description: “...its application to the number we know as Harlem Air Shaft must be questioned. At the time of recording, the piece was known as Rumpus in Richmond, suggesting that Duke's famous program was something of an afterthought." ${ }^{4}$ In my Ongakugaku essay, I wrongly asserted that Whaley used ink-so dark was his writing. ${ }^{5}$ These can be found in Series 1 (1A Music Manuscripts), Collection 301, Box 141.

${ }^{6}$ Given the importance of the brass throughout the work, this title could be another of Ellington's wordplays: "Brassiere" would be "brass" plus "ear," implying "an ear for brass." Ellington may also be playing on the title's literal meaning: the shape of the opening tune on trumpet, on music paper, has a relation to the shape of the undergarment. Incidentally, all the parts for this piece are marked "Brassiere."
} 

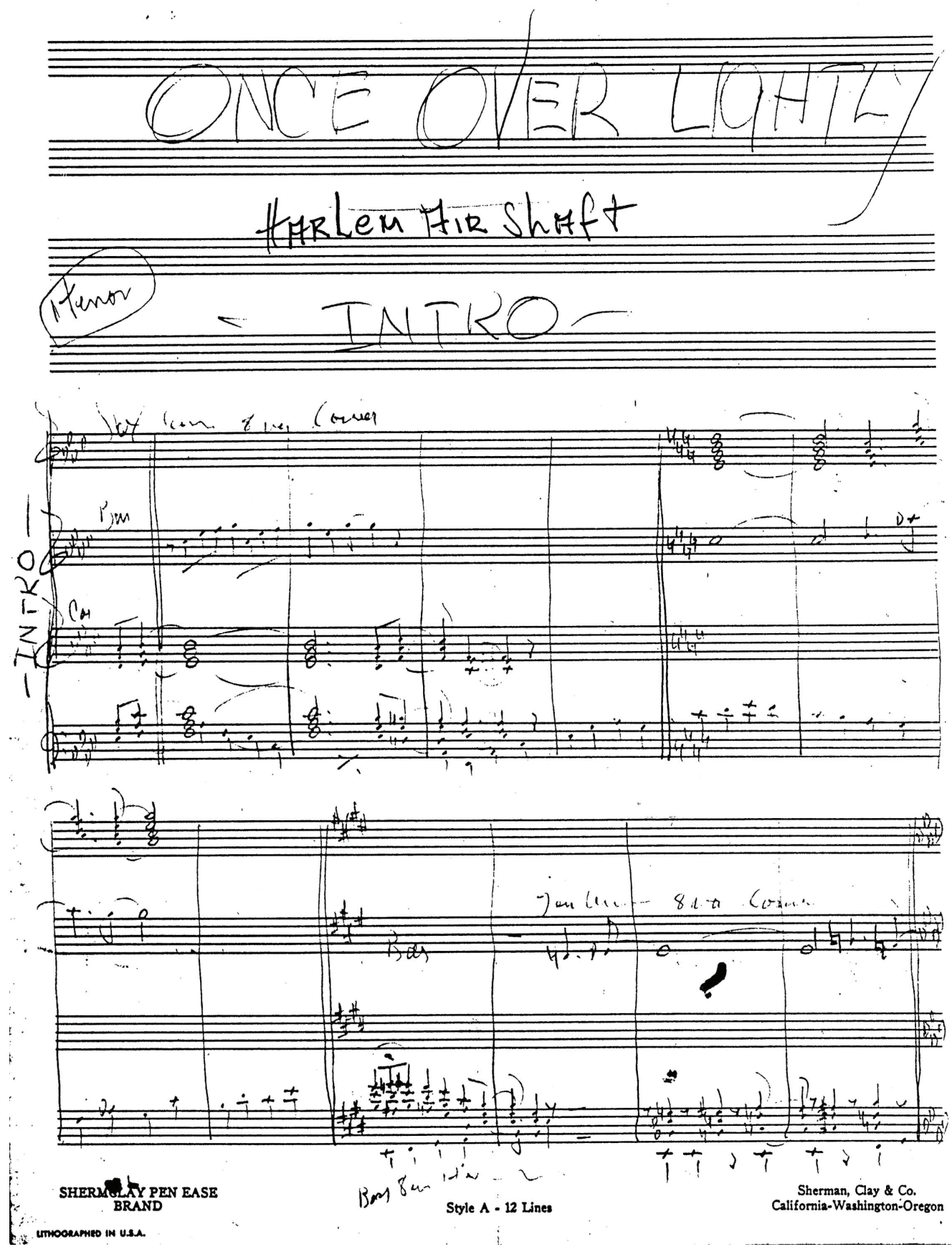

Figure 1. Score of "Harlem Air Shaft," showing "Once Over Lightly" as original title. 
The "Once Over Lightly" matter, however, is not so easily dismissed, since the music used at the actual recording session-both the score and the parts, which were copied by Juan Tizol - display that title. As mentioned, the updating on the parts to indicate the change to "Harlem Air Shaft" was done by Tom Whaley afterwards.

\section{EARLY BROADCASTS}

We'll return to this question of alternate titles a bit later. First I will investigate the supposed "time gap," as to both the title and the attribution of programmatic content. To begin with, as mentioned before, the record was released in late August, 1940 - and the physical production of records (including the printing of labels) takes some time. So, we can assume that by early August, at the latest, the ultimate title had been fixed. Yet we can push the boundary back even further.

On July 29th, 1940, just seven days after the studio recording session, the orchestra made a broadcast over the NBC Red Network from Eastwood Gardens, Detroit-and the NBC logs call the piece "Harlem Air Shaft." "The broadcast was live, and ran from 11:30pm to midnight. "Harlem Air Shaft" was the third number on the program-or the fourth, counting the band's opening piece (its signature tune at the time), East St. Louis Toodle-oo. The sequence in the broadcast was as follows, with Ivie Anderson joining the band as vocalist for numbers 2 and $5: 8$
1. Koko
5. Me and You
2. At a Dixie Roadside Diner
6. Jack the Bear
3. Harlem Air Shaft
7. Concerto for Cootie
4. I Don't Mind

An aircheck made of that broadcast includes an explicit verbal introduction to "Harlem Air Shaft." (The recording is little known, since it has never been issued publicly and circulates only among collectors; I am grateful to jazz historian Ken Steiner for bringing it to my attention.) The unidentified announcer does not

\footnotetext{
${ }^{7}$ See Luciano Massagli, The Nerw Desor-An Updated Edition of "Duke Ellington's Story on Records, 1924-1974," Part One (Milan: Luciano Massagli, Giovanni M. Volonté, 1999), 49. For updated information not included in The New Desor, see www.depanorama.net/dems/04dems1b.htm, part of the website "A Duke Ellington Panorama," sponsored by the Duke Ellington Music Society (DEMS). For the NBC logs, see WEAF Master Logs, NBC Collection, Library of Congress, Motion Picture, Broadcasting, and Recorded Sound Division.

${ }^{8}$ The logs unearthed by Steiner list two other pieces that were apparently scheduled for the broadcast but crossed out: "My Greatest Mistake" and "Date with a Memory." The latter work was apparently never recorded by Duke, at least under that title.
} 
merely declare the title, but also refers swiftly to the music's programmatic content:

The following is Duke Ellington's own rhythmic impression of the themes and sounds heard in an apartment courthouse ${ }^{9}$ in Harlem. It bears the very [demonstrative?] title of "Harlem Air Shaft."

The word "demonstrative" is hard to discern, but it's my best guess as to what the announcer said. In this context, the word seems to suggest that the piece was meant to illustrate what goes on in an air shaft in Harlem. (Another meaning of demonstrative- “outwardly emotive"-doesn't work as gracefully in the sentence.)

Whether the word is, indeed, "demonstrative" or another adjective may never be certain. But what is clear-and it is the crucial point - is that within a week of the studio recording, Ellington was calling the piece "Harlem Air Shaft," with at least a rudimentary programmatic introduction. True, most of the specific details found in Boyer's article are absent. But one would hardly expect an expansive presentation of programmatic details under the time constraints of a live broadcast, especially in those days. And this is not Ellington speaking, but a local announcer. The announcer may have thought it unwise to speak at length on live radio, even if Ellington had told him about the piece in more detail.

As Ken Steiner has noted, the band's Eastwood Gardens engagement-which extended from the 26th to the 31st of July-was broadcast every night at 11:30, except for July 28th, a Sunday. It is therefore possible, even likely, that "Harlem Air Shaft" was introduced by that name on air as early as the 26th-especially since Ellington hardly ever missed a broadcast opportunity to draw attention to his most recent recordings. That would put us within a mere four days of the studio recording. Unfortunately the radio logs are no help on this point. Customarily at that time, logs were diligently maintained only for coast-to-coast radio events, and only the broadcasts from July 29th and 31st were carried nationally by NBC (on the Red Network) ${ }^{10}$ The source of the local broadcasts on the 26th and 27 th was Detroit's WWJ, ${ }^{11}$ but no logs or recordings are known to survive.

Returning to the actual announcement, notice that the announcer uses the word "themes," when "sounds" by itself might well have sufficed. This word, "themes," suggests that the announcer may indeed have heard more about the

\footnotetext{
9 The use of "courthouse" is a bit odd. Likely the announcer, in a verbal stumble, conflated "courtyard" and "townhouse."

${ }^{10}$ See Ken Steiner's self-published pamphlet, On the Air and On the Road with Duke Ellington, The Blanton-Webster Years, vol. 1 (Seattle, 2004), 9. An online edition is available at www.depanorama.net/dems/04dems2b.htm.

${ }^{11}$ Not WWI, per Ken Vail's Duke's Diary: Part I (Lanham, MD: Scarecrow Press, 2002), 184. Obviously this was a "slip of the pen," since I and J are easily confused in handwriting. WWI, out of Dearborn, Michigan, apparently went off the air in 1925.
} 
internal design of the piece directly from Ellington. As I shall now explain, Ellington quotes something like a pre-existing "theme" (or tune) in order to make a programmatic point.

\section{A SUBTLE AND SUGGESTIVE QUOTATION}

Within "Harlem Air Shaft" is an engaging musical joke. Example 1 shows the third 4-bar unit of the Intro, a passage for trombones, set in E major:

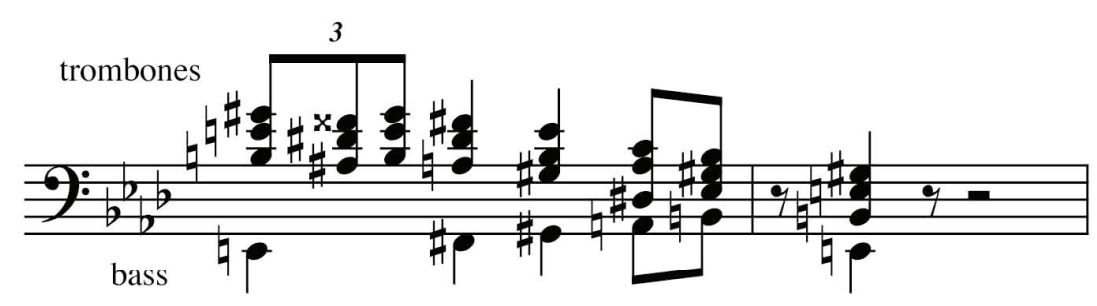

Example 1.

Perfectly good swing! But the passage is also a witty disguise of a tune that was very popular in the African-American community at the time. In the third chorus - in keeping with the plan of matching "titles" and "chapters"-Ellington repeats the passage, retaining the instrumentation (trombone trio), but reshaping it (as seen in Example 2) to fit gracefully with the key of Ab. As we hear this second instance of the passage, and note the enharmonic reinterpretation of $\mathrm{G} \sharp$ as $\mathrm{A} b,{ }^{12}$ the quotation becomes clear: we've been hearing the song "I Love Bread And Butter" all along!

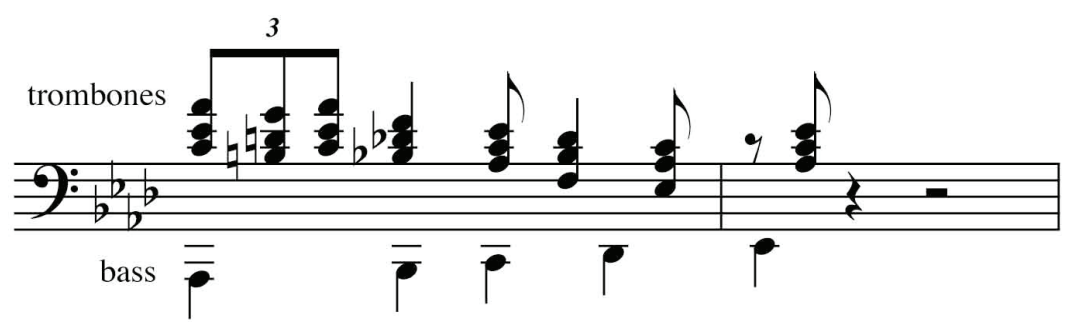

Example 2.

12 The titles of many jazz compositions are wordplays, often direct puns. Ellington participated richly in this tradition. By analogy, this enharmonic relation of $\mathrm{G} \#$ and $\mathrm{A}$ b accomplishes precisely what a verbal pun does. It makes for a simultaneous experience of sameness and difference: sonic equivalence at one with distinction of meaning. When the meaning is radically different-and it often is - the pun, musical or verbal, has the charm of absurdist humor: logical and impossible at once! A good case can be made that the finest and most consistent body of punning in 20thcentury American culture appears in jazz. The only real competition (from the verbal side) can be found in the Marx Brothers, who surely score the very highest marks in the field. 
At this point in his career, Ellington rarely quoted other writers' melodies within his own original work. And on the few occasions he did, never, as far as I know, did he do so with this level of sophistication, this degree of sonic camouflage. Ellington worked the quotation into his composition with such loving care and good humor that it could not have been a mere throwaway.

The lyrics to the song play up the food/love relation central to the "storyline" in Ellington's 1944 program for "Harlem Air Shaft." Over the years, the lyrics to "I Love Bread and Butter" have undergone some variations. But by far the likeliest set of words for the opening stanza circa 1940 - as confirmed for me by Dr. Richard Crockett of the Eubie Blake National Jazz Institute and Cultural Center in Baltimore-was:

I love bread and butter, She loves toast and jam. I know how she likes it, I'm her lovin' man.

Dr. Crockett knew Ellington at the time, and assures me that the composer was definitely aware of the song. In fact, he remembers him singing it!

Now, in Ellington's 1944 program, the food references are to "turkey" and "dried fish"-no breakfast imagery. But does this discrepancy really matter? Perhaps Ellington originally had breakfast in mind, and then-four years later, as he riffed on his memory - "transposed" breakfast into meals of fish or turkey. Art, after all, is hardly ever a simple, unvarnished transcription of experience. It is, instead, a purposeful reshaping of raw experience to give it an expressive purpose, a wider and deeper context, and perhaps a clearer outline. As William Wordsworth famously noted in relation to his poem "Daffodils," poetry is "emotion recollected in tranquility." In the process, specific details may change, even as the core event is still discernible. In "Daffodils" he presents himself as wandering all alone. Yet a journal entry by Dorothy Wordsworth-written two years before the poem-confirms that she and her brother came upon the scene described in the poem together. Her journal includes many of the images-and even some of the specific language-that William employed in crafting the poem. ${ }^{13}$

In any case, in the lyrics Ellington quotes and in his 1944 program for "Harlem Air Shaft," love and food-two of life's primal realities-intertwine. The precise content of the meals is a rather secondary matter. It is also possible (though I won't press this point) that, in 1940, Ellington, thinking of breakfast, thought of the title "Once Over Lightly" as a play on "once over easy," the well-known instruction for preparing eggs. "Once Over Lightly" has long been an acceptable

${ }^{13}$ Cited and discussed in Yang Ye, Chinese Poetic Closure (New York: Peter Lang, 1996), 1-3. 
alternative phrasing, and based on (admittedly anecdotal) research I have undertaken with jazz fans who ordered eggs in the early 1940s, "once over lightly" may even have been the more popular term at the time!

Flipping this last speculation aside, one certainty emerges: Ellington's quotation of "I Love Bread and Butter" delivers the "coup de grâce" to the idea that "Harlem Air Shaft" was ever named "Rumpus in Richmond." It's hard to see Ellington (even Ellington!) inspired by a picture of Virginians in a rumpus over whether breakfast ought to have "toast and jam" or "bread and butter." Moreover, the actual "Rumpus in Richmond" has an opening solo trumpet fanfare figurean almost quasi-military call to battle-which seems appropriate to that title.

\section{THE QUESTION OF FORM AND CONTENT}

Returning, then, to the key question: is the true title "Once Over Lightly" or "Harlem Air Shaft"? Perhaps it is a mistake to formulate the question so starkly, as if the titles were mutually exclusive. As I hope to show, both titles are true; both are appropriate and revelatory of what happens in the music. Apparently the title "Harlem Air Shaft" did come later, if only slightly. But I propose that the reality behind that title - the core programmatic content of the piece-inspired Ellington earlier. My belief is that as Ellington created this music, his initial inspiration already had programmatic content, and that he searched for material (as witnessed by the quoted song) and a form (that unique title/chapter design) that would enable the program to "come across."

A composer of programmatic music may or may not choose to make public its extra-musical content. Moreover, if a composer is excited by the formal and structural innovations of his piece, he might well be tempted-out of professional pride - to point listeners towards those innovations by choosing a title hinting at the formal design of the music rather than its programmatic content. And the design of "Harlem Air Shaft" is, indeed, a case of "Once Over Lightly." The phrase (which, incidentally, entered the American vernacular just around this time $)^{14}$ means to give something a quick-even superficial-treatment: to

\footnotetext{
${ }^{14}$ There was a 1938 movie titled "Once Over Lightly," spoofing college life. The phrase "once over," meaning "a quick, penetrating glance," is also apropos to our discussion. According to Partridge's Concise Dictionary of Slang and Unconventional English, ed. Paul Beale (New York: Macmillan, 1989), 314, "once over" entered the American language around 1919; doughboys returning from WWI had learned it from British soldiers. Incidentally, in the folder for the parts for "Harlem Air Shaft" at the Smithsonian - on the reverse side of one page of Harry Carney's baritone part-is a page marked not for Carney, but for "Barney" (Bigard), with the title "Once Over" (not "Once Over Lightly"). Was Ellington considering this title as well? To add to the mystery, the music on this page is not "Harlem Air Shaft" at all—it's Bigard's tenor part for "All Too Soon," which was recorded at the same session (July 22, 1940).
} 
"sketch" rather than to "fill out." This is just what the Intro does, relative to the main body of the work.

The manuscript tends to back up this possible reconstruction of Ellington's thought process. Consider: the word "Intro" is presented twice on the opening page-first high up, centered, in large letters; and then, written vertically in smaller letters, directly to the left of the first four-stave unit of the score, just before the opening notes of the piece (see Figure 1). I conferred with several Ellington scholars and archivists, and not one could think of another instance of his placing the word "Intro" twice on a manuscript. This page is as unique visually as the composition, from a structural perspective, is without audible parallel. One might suggest that Ellington, as he thought of how the piece should be announced, came to realize that-amazing as his structural plan was-the title "Once Over Lightly" was far less likely to interest general audiences (and hence generate sales for the forthcoming record) than a title pointing to the music's colorful storyline and engaging imagery. Ellington, after all, was no ivory-tower composer; he had a payroll to meet!

The key point is: there is no actual schism in the music. The eventual title, "Harlem Air Shaft," merely emphasizes content rather than form. And the ability to make form and content one is requisite for an artist in whatever field: music, literature, cinema, dance, or the visual arts. As the great American philosopher Eli Siegel observed, "All beauty is a making one of opposites, and the making one of opposites is what we are going after in ourselves." 15 If we try to understand "Harlem Air Shaft" from one perspective without the other-if we think about form and neglect content, or visa versa-we impoverish our experience of the music.

\section{A PROVOCATIVE SHEET OF MANUSCRIPT PAPER}

In the Ellington Collection at the Smithsonian, the folder that contains the parts to "Harlem Air Shaft" 16 also contains a single sheet that appears to be a sketch for the fourth chorus - the "shout" chorus (see Figure 2). On this sheet, in a series of single staves, the first 24 measures of that chorus are presented in four-part, closed-position harmony. In keeping with what we see in the full score, this point in the music is marked "Tutti" and is given the rehearsal letter D. Written in ink at the top of this sheet, in Whaley's hand, are the words "Harlem Air Shaft." What is provocative is that the title "Once Over Lightly" is not present at all.

\footnotetext{
15 Eli Siegel, The "Modern Quarterly" Beginnings of Aesthetic Realism: 1922-1923 (New York: Definition Press, 1997), 13.

${ }^{16}$ Folder C; the manuscript was in folder D.
} 


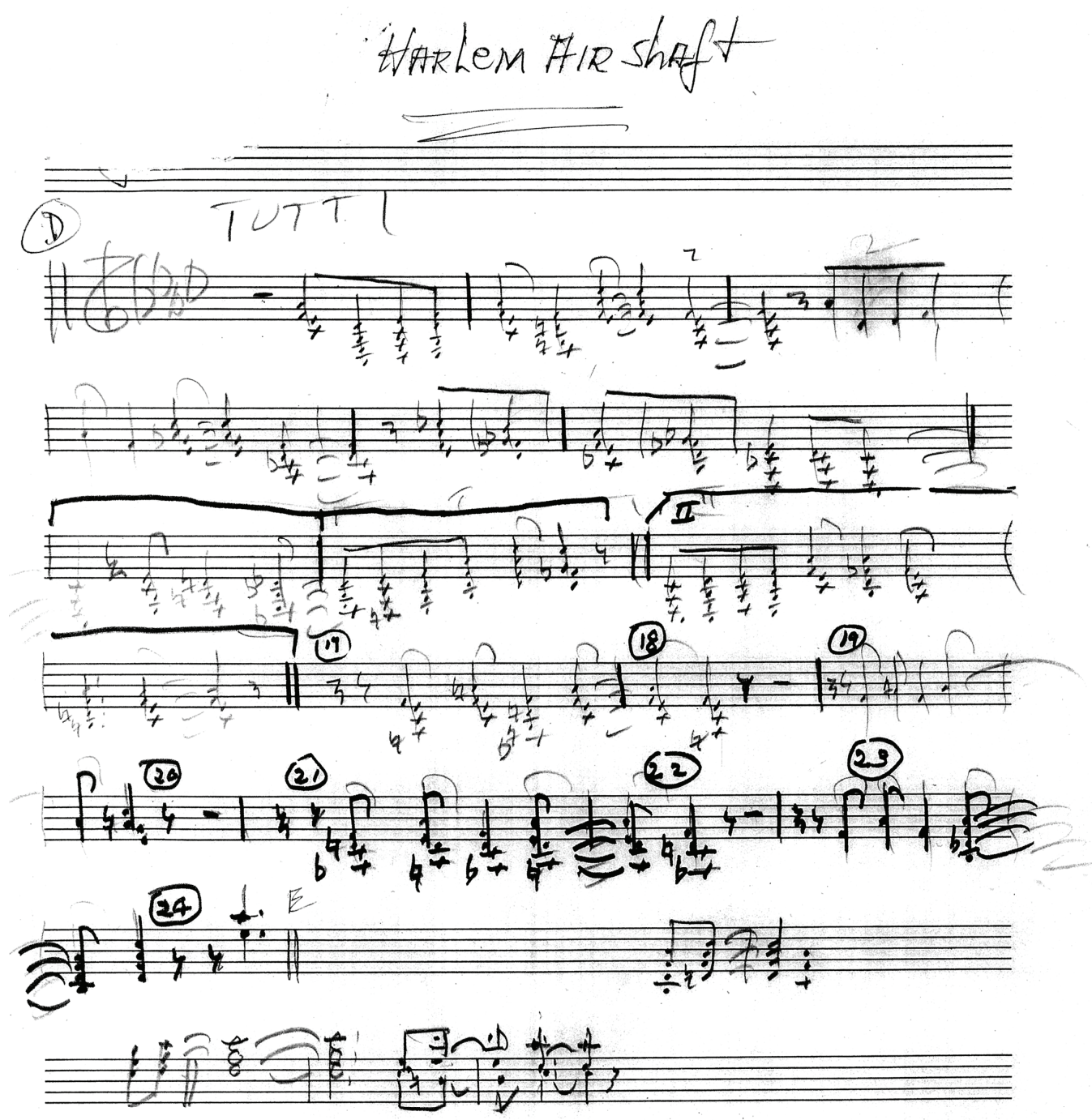

Figure 2. Sketch for fourth chorus of "Harlem Air Shaft."

Also intriguing are the significant differences between the chords found on this sheet and those found on the score and the 1940 recording that arose from that score. And most fascinating of all, this "sketch" is in the hand of Billy Strayhorn. ${ }^{17}$

When precisely was this sheet written? Certainly, after the full score was completed. Why? - because it has the correct rehearsal letter on it. The question, then, is how much later. As far as I know, no recorded performance by the band makes

${ }^{17}$ My opinion, confirmed by that of David Berger. 
use of the voicings found on this page. I think it likely that the sheet is from 1940, as the voicings on it are hardly in keeping with the later Strayhorn. A Strayhorn "rewrite" even from the mid-40s would presumably be more adventurous. This sketch, on the contrary, is less sophisticated harmonically than what we find in Ellington's score.

What results from these considerations? Perhaps Ellington, after finishing the score, had second thoughts about this chorus and asked Strayhorn to present him with an alternative. Lest anyone wonder whether Ellington would have entrusted Strayhorn with such a significant role at such an early date, remember that Strayhorn devised the final form for "Jack the Bear," stitching together and shifting around various passages Ellington had composed. And "Jack the Bear" was recorded months earlier, on March 6.

Notice on the sketch manuscript that measure numbers (counting from rehearsal letter D) have been placed over the music, and some chords have been written over in ink - in what does not appear to be Stayhorn's hand. The flags for the inked-over eighth-note chords are connected to their stems, while the penciled chords throughout the sketch have flags that tend to fly separate. The ink and measure numbers strongly imply a separate copyist. All this would have been unnecessary had Strayhorn simply played these alternate voicings for Ellington on the piano. So it appears this alternative to rehearsal $\mathrm{D}$ was played by the band, and tested by Ellington - and rejected. I, for one, am glad of it, since the voicings on the recording are much more interesting: at once more surprising and more suavely convincing. Example 3 juxtaposes the opening measures of the Strayhorn sketch with the score Ellington used for the recording.

\section{Ellington:}

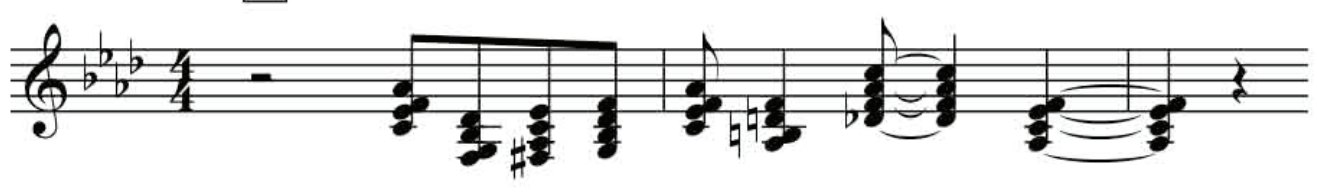

\section{Strayhorn:}

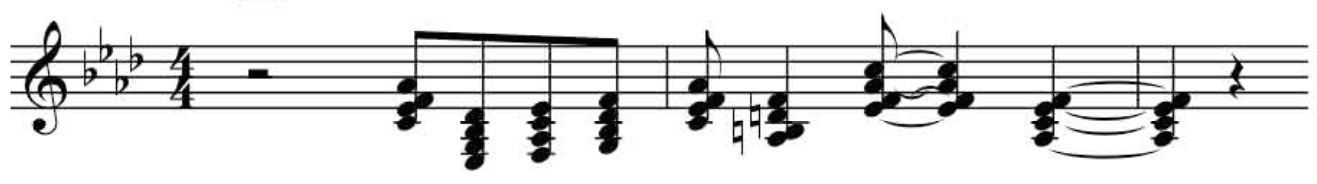

Example 3. Ellington's "Harlem Air Shaft" score juxtaposed with Billy Strayhorn's sketch. 
Let us return to the fact that "Once Over Lightly" is not found on the sketch sheet in Figure 2. What we do see is "Harlem Air Shaft," but as that title is written in Whaley's hand, it is obviously a later addition. Crucially, there is no title in Strayhorn's hand. So what most likely happened is that when this sketch sheet was handed to a copyist (Juan Tizol?), Strayhorn told him verbally that the music on it was for the piece then known to the band as "Once Over Lightly."

Yet there is an alternative scenario: maybe - just maybe - no title appeared on the original Strayhorn sketch because Ellington had not yet settled on one. If this is indeed what happened, it would suggest that when the score was initially completed by Ellington, it had a blank space at top, and "Once Over Lightly" was added later. Nothing in the layout of Figure 1 prohibits this possibility.

Whatever one makes of these speculations, the brand names on the manuscript papers do suggest a possible chronology for the composition. The full score is written on 12-stave paper printed by Sherman, Clay \& Co. of "CaliforniaWashington-Oregon" (see the bottom of Figure 1). The sketch sheet, with 10 staves, was printed by Passantino, located in New York. Certainly Ellington and his copyists may have carried around paper from different locations at any given time. Yet reviewing the band's schedule in 1940, we find it was on the West Coast from March 29th (in Tacoma, Washington) to May 4th in Hollywood, where Ellington had a recording session for "Bojangles," Cotton Tail," "Never No Lament," and "Blue Goose." By June 7th, the orchestra was back in New York for a week at the Apollo Theatre, after which they traveled to various venues in the East, returning to New York for a Savoy Ballroom engagement on June 23rd and the July 22nd recording session that included "Harlem Air Shaft." Since it was Ellington's custom to try out and perfect pieces on the road before bringing them to a studio recording session, it is reasonable to think the score itself was written between March 29 and May 4, and this "revised section D" was composed by Strayhorn sometime on or after June 7 th.

As a "coda" to this subsection of the essay, let me mention one other engaging sheet of music found in the parts folder for "Harlem Air Shaft": the part that Tizol wrote for Sam Nanton (marked "Tricky") for the recording session. The words "Harlem Air Shaft" appear on it, along with "Once Over Lightly." So far, nothing unusual. What is unusual is that whereas Whaley wrote the new title in for every other player, Nanton did so himself, and in delightful, child-like, openfaced block letters. Who knows when? Who knows why?

\section{HOW EXACT IS THE PROGRAM?}

Having investigated the manuscript evidence, and the contemporaneous on-air recordings, we are now in a better position to consider the truthfulness of the 1944 program found in Boyer's New Yorker portrait. Let us begin by recalling the 
radio announcer's introduction of July 29th, 1940. There is a distinct possibility that Ellington wrote this introduction himself, and handed it over to the announcer to read. Duke was known to do such things. To my ear at least, there's something very "Dukish" about the tony use of a word like "demonstrative." Ellington throughout his career employed this kind of verbal elegance as he introduced his music.

Duke may well have embellished, or even altered, some programmatic details during the four years that elapsed between the recording and the Boyer interview. After all, there is no evidence of a detailed program written out before the composition was recorded, such as exists for Black, Brown and Beige. One cannot, therefore, be certain which programmatic elements came before, during, or after the actual composing. At the same time, analysts need to be very careful on this question. For it is wrong to say that a composition is authentically programmatic only when it has a settled storyline before any music is written down. A composer may begin work with a general picture in mind, and then bring that picture into sharper focus precisely as the abstractly musical aspects of his material take shape. During this creative dialectic - this inspired "tussle" between form and content, sound and sight - more detailed programmatic pictures may arise in his mind and inform his musical choices.

Inspiration is always both conscious and unconscious, and it is no paradox to say that a composer may discover truths about his music while composing-or even after completing a work. This is clear enough when it comes to a composition's abstract musical relations. Many a composer discovers in retrospect that he or she did something technically - a canonic imitation, say, or an inversion of a theme-which, in the heat of the creative experience, was not a conscious decision. Even so, that technical achievement is real.

So why can't the same courtesy be shown a composer's mind when it functions programmatically? It is intellectual prejudice to think any ex post facto account of what inspired a composition must inevitably be jive. A musician may sincerely say in retrospect, "I now understand what was affecting me earlier as I wrote this part of the piece." Yet many people will invalidate any programmatic statement that cannot be proven to predate other aspects of composition. I think this attitude is unjust to the creative process, and greatly restricts the range of true scholarly research into the phenomenon of programmatic composition.

Of course some ex post facto accounts are indeed jive, and it's not easy to tell the difference. Surely our analytic method must carefully weigh two elements: the timing of the programmatic statements, and the evidence found directly in the music.

As noted, the radio announcer's introduction from July, 1940, refers to "rhythmic impressions of the themes and sounds of an apartment courthouse [sic] in 
in Harlem" and the "demonstrative title of 'Harlem Air Shaft." This seems to support the key point in Ellington's statement to Boyer in 1944: that the piece musically "demonstrates" the experience of living next to an air shaft in Harlem. If we now focus directly on the music, we find that the "I Love Bread and Butter" quotation is hardly the only evidence-or even the strongest evidence-backing up the programmatic details from the Boyer interview.

To begin with, the innovative "table of contents" form mirrors Ellington's statement that "So much goes on in a Harlem air shaft." Like the air shaft of Ellington's description, the composition-with its rapid modulations-initially sounds like a tonal jumble. Only later do the sounds settle down, to be made better sense of. Someone's first encounter with a Harlem air shaft, with its sheer energy and variety of life, would proceed in just this way. It would obviously take some time to disentangle all those sounds and know which were coming from which apartment!

More specifically, several musical passages throughout the composition fit the details of Ellington's 1944 storyline with remarkable precision. These synesthetic parallels cannot be proven definitively, but nor are they evidence of an unhinged imagination. Consider how Ellington talks about "jitterbugs." "Harlem Air Shaft" is, after all, one of the most overtly swinging and danceable of Ellington's 1940 compositions. Its abundant use of riff-figures might have been Ellington's purposeful evocation of the kind of music that jitterbuggers favored.

Among other possible parallels are these:

- In chorus two, the drums make a sudden, crashing re-entry, as the unsupported saxophones totter high above, desperately seeking a solid beat beneath. (Ellington: "The man upstairs' aerial falls down and breaks your window.")

- The lyrics to "I Love Bread and Butter" include the line "I'm her lovin' man." Thus the quotation of this song in chorus three might have been designed to evoke not only the air shaft's gastronomic smells, but also the sounds of people making love. To my ear Bigard's solo for that chorus, with its supple lines, does seem to draw the piece into a more sensuous mood. In Ellington's 1944 program, dinner and love, after all, appear in the same sentence: "You hear fights, you smell dinner, you hear people making love."18

- Chorus four begins with a quiet, insinuating pixie muted plunger trumpet playing what sounds like "intimate gossip floating down." The muting evokes both the nasality of gossip and its surreptitiousness.

${ }^{18}$ The full score indicates that Ellington originally planned to have Cootie Williams solo during this chorus against the trombone trio in riff accompaniment, but then decided to let Barney Bigard do so on clarinet, as we can hear on the recording. Just why, and when, this happened cannot be ascertained. 
- Eighteen measures into chorus four, the clarinet's rapid scales and sudden changes of register boldly conjure up the jitterbuggers - now in a more visual than rhythmic fashion. It is easy to picture, through Bigard's rapid glissandi, the flip of a girl over a man's shoulder, her skirt in flight. Incidentally, there is no indication in Bigard's part that he should solo in these measures. Both the score and the part say his "ad lib" should begin 25 measures in, at rehearsal letter E. Somewhere along the line, in the process of shaping the piece, the adjustment was made.

These are a few samples of the coordination of abstract musical sound and concrete lived experience that characterizes "Harlem Air Shaft." Of course such correlations could be imposed years after the fact. But the more straightforward explanation - that at least some of these "tone parallels" were in Ellington's mind as he composed "Harlem Air Shaft"-seems far more likely. It is even possible to suggest musical signposts for the laundry, the dogs, the snoring, the fighting, and the praying. These seem more speculative, at least to my ear, so I don't flesh them out here. But I will admit to a particular fondness for one other parallel: the sounds of the saxophones in chorus one suggest a coffee pot percolating!

\section{ELLINGTON'S LOVE OF DIVERSITY}

In the long run it is not necessary to nail down, in the manner of a musicological positivist, a sonic analogue for each detail of Ellington's program. It is easy enough to grant that Ellington invented some of these parallelisms later, in keeping with his overall programmatic conception. After all, improvised jazz solos work on precisely this principle: they are invented after the tune on which they are based, but are still meant to be true to it. The big picture here is that whatever the compositional process, this music — and the story that goes with it - magnificently convey the sheer hullabaloo, the untamable diversity of life as witnessed through a Harlem air shaft.

Ellington's verbal account points to — as if the music weren't enough — just how much he loved that diversity ("You get the full essence of Harlem in an air shaft...An air shaft has got every contrast"). A main point of my Ongakugaku article (which also investigated other works) was that in "Harlem Air Shaft" Ellington gave technical coherence and unity to the startling diversity of living experience. The intro alone (see Example 4) leaps through four keys, introduces at least six different thematic ideas, and presents five distinct colors: brass and saxes, piano alone, saxes alone, trombones alone, and saxes with trombones. All of this takes about a quarter of a minute. 

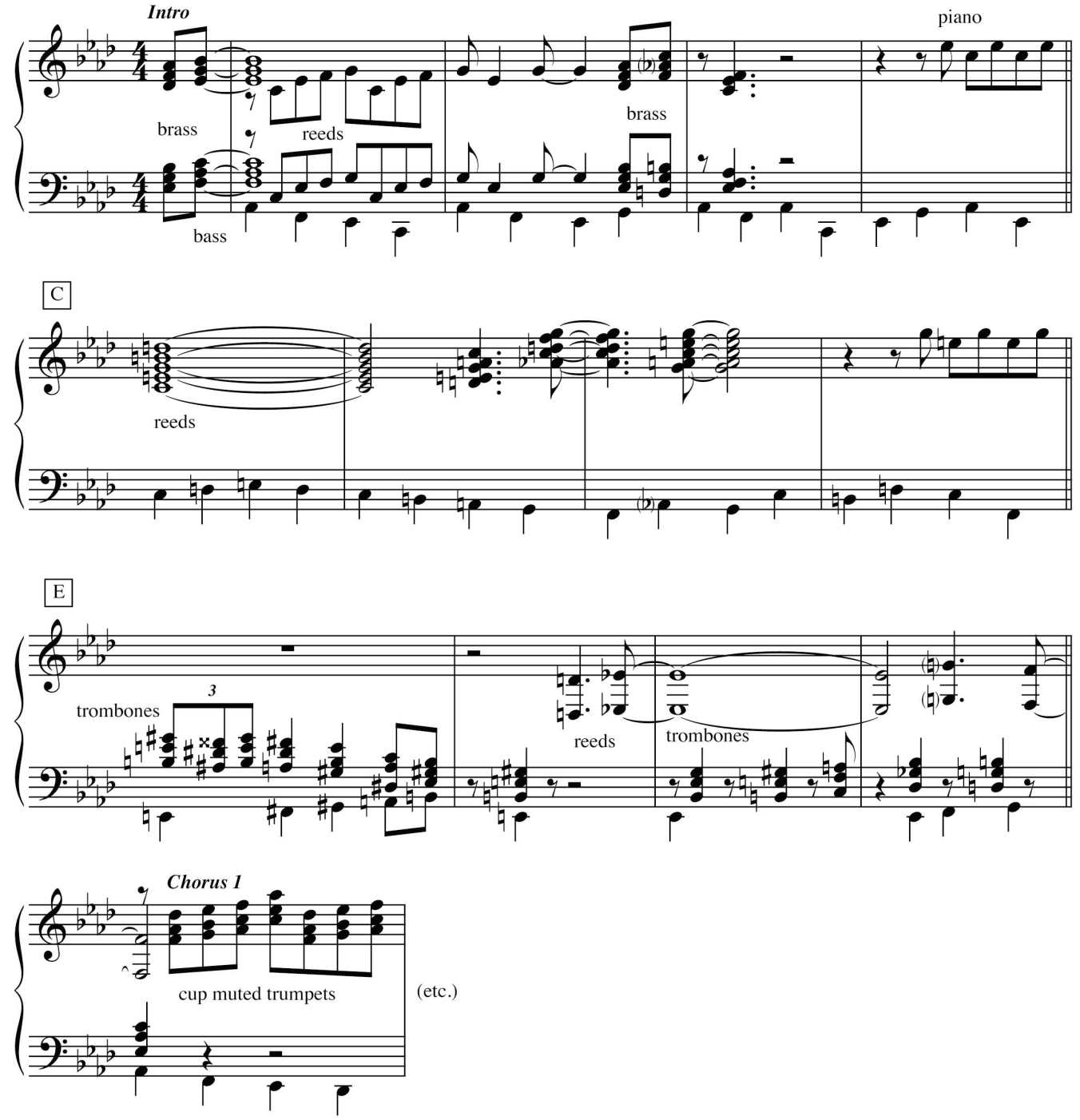

Example 4. Intro to "Harlem Air Shaft."

By basing the extended choruses on the swift foreshadowings of the introduction, and by unifying those choruses through a single key, Ellington is making an aesthetic-even a philosophic_-statement: that all the welter and colorful diversity of life has order, too, and symmetry lies within chaos. "The world is change and sameness," writes Eli Siegel in "The World, As Such, Is Present in Jazz: Some Indications," his classic essay joining jazz history and strict metaphysics. And he continues:

and it is change and sameness as one thing that is present in all art or beauty and makes that art or beauty what it is... The contemplation of the 
world or universe as one thing with many things, many things as that one thing, can make the world seem beautiful, agreeably tense, a thing of deep impact. ${ }^{19}$

These sentences, I believe, are keenly relevant to Ellington's creative achievement in "Harlem Air Shaft"-regardless of whether we hear the work as distinct programmatic coloration or simply as "absolute" music exhibiting remarkable structural daring and integrity.

It is prudent to remember that our purely "absolute" reading of a work may simply result from never having heard the composer account for its programmatic dimension. And Ellington throughout his career was deeply committed to music's programmatic potential. As he said to Boyer in that 1944 New Yorker interview:

In my writing there's always a mental picture. In the old days, when a guy made a lick, he'd say what it reminded him of. He'd make the lick and say, "It sounds like my old man falling downstairs" or "It sounds like a crazy guy doing this or that." I remember ole Bubber Miley taking a lick and saying, "That reminds me of Miss Jones singin' in church." That's the way I was raised up in music. I always have a mental picture. ${ }^{20}$

Twice in one paragraph: a "mental picture."

Perhaps scholars should give Ellington the benefit of the doubt, and take him fundamentally at his word - at least until we have evidence that he faked all this. I, for one, think that no such evidence will ever emerge, and that Ellington was simply being sincere. After all, in his youth, Ellington was determined to be a painter; the decision to become a professional musician came later. And certainly, in many of his interviews and other writings across his career, he gave ample evidence of his deep respect for programmatic music. In 1952, when he supplied Down Beat with a list of his "special preferences in classical music," every single work fell into that category: Ravel's Daphnis and Chloe, Delius's In a Summer Garden, Debussy's La Mer and Prelude to the Afternoon of a Faun, and Holst's The Planets. ${ }^{21}$

I conclude with a less quoted but equally pertinent segment of Boyer's interview. Ellington is discussing "Eerie Moan," which he composed in 1930 while the orchestra was working at the Cotton Club (the piece was not recorded until 1933). Ellington's account of "Eerie Moan" is strikingly related to his program for "Harlem Air Shaft":

\footnotetext{
${ }^{19}$ Published in The Right of Aesthetic Realism to Be Known, no. 844 (June 7, 1989): 1-2.

${ }^{20}$ Mark Tucker, ed., The Duke Ellington Reader (New York: Oxford University Press, 1993), 233.

${ }^{21}$ Ibid., 268-69.
} 
It's the voice of New York City. You're lying in bed all by yourself. The window is open. It's summer. If there was someone in bed with you, you'd be contented. But you're alone and it's very late and you listen and listen and you hear something out there that comes from millions of people sleeping, from manhole covers that give a double click as a taxi shoots over them, from tugboats far away when they whistle hoarse. You really don't hear anything single, just a kind of general breathing. You feel very alone. You moan and it seems like that's the sound you're hearing from all the city outside in the night. Only place you can hear it is New York City. ${ }^{22}$

Here is yet more evidence that Ellington was tuned into the diversity of urban sounds ("don't hear anything single") and sought ways to render these sounds musically, and to integrate them compositionally. These renderings are more quiescent in "Eerie Moan" and more rambunctious in "Harlem Air Shaft," composed ten years later. But if we are to trust Boyer's account, the only works Ellington brought up on his own-without prompting from his fellow train passengers-were precisely these two pieces. If this is a coincidence, it's a very suggestive one, indeed.

\section{ABOUT THE CONTRIBUTOR}

EDWARD GREEN has been a professor of jazz composition and music history at Manhattan School of Music since 1984, and he is also on the faculties of New York University and the Aesthetic Realism Foundation. An award-winning composer, and a Fulbright Senior Specialist in American Music, he earned his doctorate at NYU with a thesis on the late vocal music of Haydn and Mozart. His musicological publications address a wide range of subjects, including contemporary China, medieval Europe, and such modernist composers as Partch and Scelsi. His Ellington essays have appeared in Jazz Perspectives and the International Review of the Aesthetics and Sociology of Music, and he is editor of two forthcoming books: the Cambridge Companion to Duke Ellington, and Ellington Studies (co-edited with John Howland). Dr. Green is also writing a short biography of Duke Ellington for University of Illinois Press.

\footnotetext{
${ }^{22}$ Ibid., 233.
}

The Journal ofJazz Studies (JJS) is published by the Institute of Jazz Studies at the Newark campus of Rutgers, The State University of New Jersey. The editors of JJS are Edward Berger, Henry Martin, and Dan Morgenstern; the managing editor is Evan Spring. JJS is hosted online by the Rutgers University Libraries at http://jjs.libraries.rutgers.edu. 